\title{
HABILIDADE PSICOMOTORA VERSUS INTELIGÊNCIA E AFETIVIDADE
}

Maria Romana Friedlander*

FRIEDLANDER, M. R. Habilidade psicomotora versus inteligência e afetividade. Rev. Esc. Enf. USP, v. 26, n 3, p. - , dez., 1992.

Trata-se de um estudo, baseado em bibliografia, que pretende divulgar os conhecimentos atuais capazes de fundamentar a importancia da habilidade psicomotora. Descreve a relaçdo entre a ação e as capacidades de ordem mental tanto ao nivel da filogênese como da ontogénese. $O$ conceito de relacionamento entre todos os elementos que constituem o homem e o ambiente com o qual esse homem interage fundamenta as novas concepços globalizantes da pedagogia moderna.

UNITERMOS: Habilidade psicomotora. Inteligência Afetividade.

Um dos mais dificeis problemas que têm preocupado os filosofos e os pensadores desde a Antiguidade e ainda desencadeia discussőes entre os teoricos de enfermagem, é o vínculo entre a ação e as capacidades de ordem mental e as relaçóes destas com as funçóes psíquicas. Foram necessários dezenas e dezenas de anos para se conseguir alguma luz sobre o assunto. As questóes que dizem respeito à determinaçăo do pensamento pela ação ou do ato pela idéia, sob o ponto de vista da filogênese, têm recebido uma importante contribuiçáo das ciências da área da Antropologia e da Paleontologia. Por outro lado, a abordagem da evolução ontogênica tem sido subsidiada pelos estudos das ciências biológicas e daquelas ligadas a Psicologia e Pedagogia.

À luz desse conhecimento parece que já podemos afirmar que a valorização de um em detrimento do outro, para explicar a dinámica humana, náo encontra fundamentaçăo científica. Os achados científicos das várias ciências têm confirmado, ao longo do último século, a interação estreita entre todos os mecanismos onde uma fronteira nítida é quase impossf́vel de ser distinguida.

Os antropólogos afirmam hoje que não haveria pensamento sem açăo e que, por sua vez, a capacidade humana de transformar o meio ambiente por meio do ato operatório só é possível com o desenvolvimento da inteligéncia. Isto quer dizer que, por meio da sua capacidade operatória o homem estabelece relaçóes e comunica-se com o meio exterior e, a partir destas interaçőes são formuladas as idéias, os pensamentos e as inovaçōes. Por outro lado, a contínua elaboraçăo das idéias é responsável pela promoção do intenso desenvolvimento das capacidades ativas do ser humano, garantindo-lhe a evolução da própria açăo. O homem é, então produtor da cultura e esta por sua vez, modela e obriga o homem a transformar-se. Há uma profunda relação bidirecional entre a ação e a inteligência do atual ser humano.

- Enfermeira. Professora Associada da Escola de Enfermagem da Universidade de São Paulo. 
Os achados e estudos paleontológicos, como provam LINTON (1959), RUFFIE (1974) e MacLEAN (1974) e como explica MARMOTO (1984), vêm confirmar que a evolução filogenética do "homo sapiens" foi organizada por transformações anátomo-fisiológicas, particularmente, a posição vertical, a face curta e a liberação das mãos durante a locomoção que permitiram uma nova conformaçăo e volume cerebrais, o aparecimento da linguagem e a riqueza da motilidade dos membros superiores. A libertação das mãos implica forçosamente na atividade e desenvolvimento da técnica e dos instrumentos ampliando o âmbito da ação humana sobre o seu meio exterior. "Posiçăo ereta, face curta e mão livre durante a locomoção e posse de utensílios amovíveis são verdadeiramente os critérios fundamentais da humanidade" (LEROI-GOURHAN, 1964a). Uma das características dos Primatas é fazer intervir em primeiro lugar a măo e esta utilização prepara as vias pelas quais a ação do homem se manifestará. $O$ homem, sob esta abordagem, é o primeiro possuidor de utensílios na escala da evolução das espécies (LEROI-GOURHAN, 1964b).

O surgimento das características motoras humanas possibilitaram também a elaboraçăo dos vários sons e, conseqüentemente, a linguagem falada. Esta nova aquisição permitiu o aparecimento de códigos e, portanto, dos significados, das imagens, dos mitos, da cultura e do conhecimento. Se a liberdade da mão permite a palavra, é esta que dá origem à cultura, conclui MARQUES e SANTOS (1985).

São, explicam FONSECA (1982) e MARMOTO (1984), as interaçð̃es recíprocas entre o homem e seu ambiente e o desenvolvimento da mão, do cérebro e da linguagem as origens da sociedade humana. A atuaçăo sobre o meio por intermédio do ato operatório e da linguagem fazem o homem atingir um nível em que a praxis se converte em símbolo abstrato. Mas, antes, a ação sensorio-motora já tinha, por sua vez permitido desenvolver as faculdades mentais enquanto o cortex cerebral se ia complexificando o seu volume aumentando uma vez que a face deixava-lhe espaço para tanto.

"Vejo um animal menos forte do que alguns, menos ágil do que outros mas, ao fim e ao cabo, é de todos o mais bem organizado."

\section{JEAN-JACQUES ROUSSEAU}

Sob o ponto de vista da evolução ontogênica do homem, estudos e investigaçóes da área de Psicologia tem, também, confirmado que "pensamento e ação não são polos opostos mas interatuantes, não tendo um mais peso do que o outro" (MARMOTO, 1984). Se a maturação do sistema nervoso é fundamental para explicar o desenvolvimento humano, ela não se forja sem as influências sociais às quais está sujeita a criança.

RUFFIE (1974) confirma que "a atividade psíquica do homem repousa sobre uma base psicológica" e FONSECA (1989) explica que "ontogeneticamente as aquisições da motricidade estão primeiro que as aquisiçōes do pensamento". Explanando sobre o assunto, o autor confirma que é a "própria motricidade que leva ao desenvolvimento do cérebro, ela é um pré-requisito da mielinazação". Mais adiante, o mesmo autor continua dizendo que "sem movimento não há desenvolvimento nem pensamento", e "por alguma razão", o desenvol- 
vimento adequado da motricidade constitui a via para um desenvolvimento intelectual ajustado".

BONNET (1988) confirma as palavras de Fonseca quando afirma que psicólogos, psico-fisiológicos e pedagogos reconhecem atualmente que o desenvolvimento do ser humano não sơ da compreensão mas principalmente da ação.

Para a análise das relaçōes entre os mecanismos mentais e a capacidade operatória na evolução ontogénica do ser humano, encontramos contribuiçőes de extrema importância em Piaget e Wallon (FONSECA, 1988).

Os trabalhos do psicólogo e cientista suiço, na metade deste século, demonstram a necessidade da interação global de todo o ser humano no desenvolvimento da inteligencia. Para Piaget segundo RAPOSO (1983) e FONSECA (1988), não é a experiência que precede a capacidade mental e nem esta determina aquela. Piaget ultrapassa esta questão explicando o desenvolvimento humano por meio de interaçóes dinâmicas entre o homem e o seu meio exterior como um processo contínuo de adaptação. Apesar de aceitar a necessidade do homem estar estruturado sob o ponto de vista biológico, esta organização aperfeiçoada só se verifica com a participação concomitante da atividade mental (MIZUKAMI, 1986).

Ainda, segundo RAPOSO (1983) a adaptação para Piaget comporta os processos de assimilação e acomodação onde o primeiro consiste em "transformar as percepçóes até torná-las idênticas ao próprio pensamento, quer dizer, aos esquemas anteriores" (Piaget, citado por RAPOSO, 1983). É a assimilação que permite que uma nova situação ou coisa real seja integrada num conjunto de experiências e conhecimentos para os quais já existe um esquema anterior (MIZUKAMI, 1986). "O movimento constrói um sistema de esquemas de assimilação e organiza o real a partir de estruturas espaço-temporais e causais" (FONSECA, 1988). Este mesmo autor ainda nos informa que Piaget considera que a motricidade interfere na inteligência mesmo antes do aparecimento da linguagem.

A sofisticação e complexidade dos esquemas perceptivo-motores podem definir a motricidade uma vez que o experimentado $e$ introjetado no proprio corpo e reflete o equilíbrio do ser humano com seu meio exterior. Portanto, as estruturas mentais e motrizes, segundo Piaget, conservam relaçð̋es integradas e dinâmicas não podendo ser explicada uma sem haver a interferência da outra.

Wallon contribuiu para a compreensão dos vínculos entre a motricidade e a capacidade sensorio-afetiva humanas. Os estudos de Wallon e Piaget completam-se numa mesma tendéncia e abordagem totalizante do desenvolvimento humano.

Como afirma FONSECA (1988) "a obra de Wallon assinala bem a importância da motricidade na emergência da consciência". Wallon preocupouse, na primeira metade deste século, com a co-ocorrência das relações constantes e recíprocas entre as alterações das funçōes afetivo-ativas. Estabeleceu-se rigorosamente um modelo de intervenção útil, não só para a corrente médico-pedagógica, como para a educação física e a reeducação psicomotora. É ainda de Wallon a afirmação "o movimento é inicialmente a única expressão e o prímeiro instrumento do psiquismo" (CAMUS, 1981). Deve-se a este autor a paternidade do que se chama escola francesa da psicomotricidade e são ainda suas idéias que dirigem e orientam estudos e estudiosos daquela área (GUILLARMÉ, 1983). 
Assim, somos obrigados a renunciar a qualquer valorização unidirecional em relação ao tonus, à atitude ou à emoção, bem como à oposição entre os aspectos e estruturas biológicas e psíquicas. O desenvolvimento do ser humano, desde a sua concepção ao estado de adulto, bem como o seu "estar no mundo" não comporta qualquer setorização. Qualquer tentativa de desmembramento em partes só será útil sob o ponto de vista da sistematização ou para auxiliar a compreensão do todo. Na realidade o homem é global e seu dinamismo é produto do todo do seu ser e do intercâmbio deste com o ambiente exterior, de forma contínua.

Os pedagogos que mais influência têm exercido na pedagogia atual, como Carl Rogers e seus seguidores, trabalham a partir da pessoa como um todo e do relacionamento integral entre todos os elementos que constituem o ambiente com o qual essa pessoa interage (ROSEMBERG, 1977).

FRIEDLANDER, M. R. Psychomotor skills "versus" inteligence and affection. Rev. Esc. Enf. USP, v. 26, n. 3, p. - , dec., 1992.

It is an study, based on specific Bibliography, which purpose is to divulge up dated knowledge capable of establishing the importance of psychomotor skills.

The article also describes the relation between the action and mental capabilities, both in the phylogenesis and ontogenesis level.

The notion of relationship between all aspects that make up the human being and the environment with which man interacts, confirms the new global conceptions of the modern pedagogy.

UNITERMS: Psicomotor skills. Inteligence. Affection

\section{REFERENCIAS BIBLIOGRÁFICAS}

1. BONNET, J. P. Vers une pédagogie de l'acte moteur. 2éme ed. Paris, Editions Vigot, 1988.

2. CAMUS, J. le. L'Enfant maladroit. Paris, Presses Universitares de France, 1981.

3. FONSECA, V. da. Filogenese da motricidade.Lisboa, Ediçöes 70, 1982.

4. FONSECA, V. da. Contributo para o estudo da gennese da psicomotricidade. 4 ed. Lisboa, Editorial Notícias, 1988.

5. FONSECA, V. da. Desenvolvimento humano: da filogênese à ontogênese da motricidade. Lisboa, Editorial Notícias, 1989.

6. GUILLARMÉ, J. J. Educação e reeducação psicomotoras. Porto Alegre, Artes Médicas, 1983.

7. LEROI-GOURHAN, A. Ogesto e a palavra: I - a técnica e a linguagem. Lisboa, Ediçōes 70, 1964(a).

8. LEROI-GOURHAN, A. O gesto e a palavra: II - memórias e ritmos. Lisboa, Ediçōes 70, 1964(b).

9. LINTON, R. O homem: uma introdução à antropologia. 3 ed. São Paulo, Livraria Martins, 1959.

10. MACLEAN, P. D. Bases neurologiques du comportement d'imitation chez le singe-6cureul. In: MORIN, E.; PIATELLI-PALMARINI, M. L'Unite de l'homme: I - le primate el I'homme. Paris, Editions du Seuil, 1974.

11. MARMOTO, I.; FERREIRA, L. R.; GARRĀO, M. Filosofia. Lisboa, Texto Editora, 1984.

12. MARQUES, A.; SANTOS, L. R. dos. Filosofia 1. 7 ed. Lisboa, A regra do Jogo Ediçð̃es, 1985.

13. MIZUKAMI, M. da G. N. Ensino: as abordagens do processo. São Paulo, E. P. U., 1986.

14. RAPOSO, N. V. Estudos de psicopedagogia. Coimbra, Coimbra Editora, 1983.

15. ROSEMBERG, R. A pessoa como centro. São Paulo, E. P. U., 1977.

16. RUFFIÉ, J. Le mutant humain. In: MORIN, E.; PIATELLI-PALMARINI, M. L'Unite de l'homme: I - le primate et l'homme. Paris, Editions du Seuil, 1974. 